ESPERANZA VERA, LUZ DARY ARIAS ZULMA BUITRAGO*

\title{
BUILDING UP LEARNERS' AUTONOMY AND COOPERATIVE ASSESSMENT
}

\section{Resumen}

El desarrollo del concepto de autonomía en los estudiantes reviste una gran importancia en la enseñanza de las lenguas actualmente. El presente artículo, recoge la experiencia de siete docentes de la Universidad Pedagógica Nacional al implementar el concepto de autonom ía como base de un modelo colaborativo para guiar y al mismo tiempo evaluar de una manera unificada, el proceso de aprendizaje de la lengua inglesa en los estudiantes en los tres primeros semestres inscritos en los dos programas que ofrece el Departamento de Lenguas.

Para la elaboración del Modelo de Aprendizaje Autónomo y Evaluación Colaborativa, se tuvieron en cuenta diferentes factores que afectan el aprendizaje y evaluación de una lengua. En consecuencia, el artículo incluye una descripción del perfil de nuestros estudiantes en cuanto a sus estilos de aprendizaje, dominancia cerebral, locus (lugar) de control, cambios en sus actitudes hacia la evaluación y resultados obtenidos en evaluaciones formales. Ademas, se incluyen, de manera general, algunos de los factores que afectan el desempeño del estudiante en la ejecución de tareas, algunos aspectos que influyen en el aprendizaje de la lengua extranjera, entrenamiento en el uso de estrategias de aprendizaje, co-evaluación y auto-evaluación.

\section{Abstract}

Encouraging learner autonomy is a must in current language teaching trends. This article presents the experience 7 teachers at Universidad Pedagógica Nacional have had implementing the concept of autonomy as an underlying construct of a cooperative model to guide as well as to assess in a unified way the English learning process of students enrolled in the first three semesters of the two programs offered by the Language Department.

Different factors affecting language learning and evaluation were taken into account to develop the Autonomous Learning and Cooperative Assessment Model we are proposing. Thus, the article includes a description of our students' profile in terms of their learning styles, brain-dominance, locus of control, changes in attitudes towards evaluation, and results obtained in formal evaluations; besides, it includes a general overview of factors affecting student performance on given

\footnotetext{
*Profesoras de la Universidad Pedagógica Nacional. 
language tasks, some aspects that affect language learning, strategy training, selfassessment, and peer-assessment.

\section{Keywords}

Autonomy, Strategies, Strategy Training, Assessment, Self-assessment, Peerassessment.

Some of the main concerns we, as teachers, nomally have is how to enhance our students' learning and how we can empower them to be autonomous leamers and to be able to evaluate their learning in a cooperative way. In that quest, we frequently wonder which aspects exert more influence on the language leamers and their learning processes and what must be done to balance those aspects in order to get the most of them. To achieve this purpose, we have designed a model which embraces the two processes.

To build up autonomy, viewed as "the ability to take charge of one's own learning" (Holec, 1979:3) some teachers at Universidad Pedagógica Nacional have tried to achieve two main goals: 1) to understand and help students understand which factors take part and interact in the process of using their language knowledge to solve tasks in the classroom context ${ }^{1}$ and 2) to guide students through the development of their "strategic competence." On the other hand, to evaluate their learning process in a cooperative way, we have created and implemented a process called peer-assessment, which will be described later.

\section{Autonomous Learning}

Goal 1. To begin with the achievement of the first goal, we have started using our own version of an interactionalist model proposed by Carol Chapelle (1998: 58). Although this model was designed to carry out content analys is of a test, we can use it to provide an overview of the factors which need to be taken into account when designing language tasks for our students, when trying to assess our students' language knowledge and performance or when trying to make them assess those areas themselves. Let us start by having a look at Chapelle's model.

\footnotetext{
${ }^{1}$ Although this goal is not explicitly stated in our model, which will be presented later, it underlies the whole process of autonomous learning.
} 


\section{Content Analysis Model ( Adapted from Carol Chapelle's, 1998)}

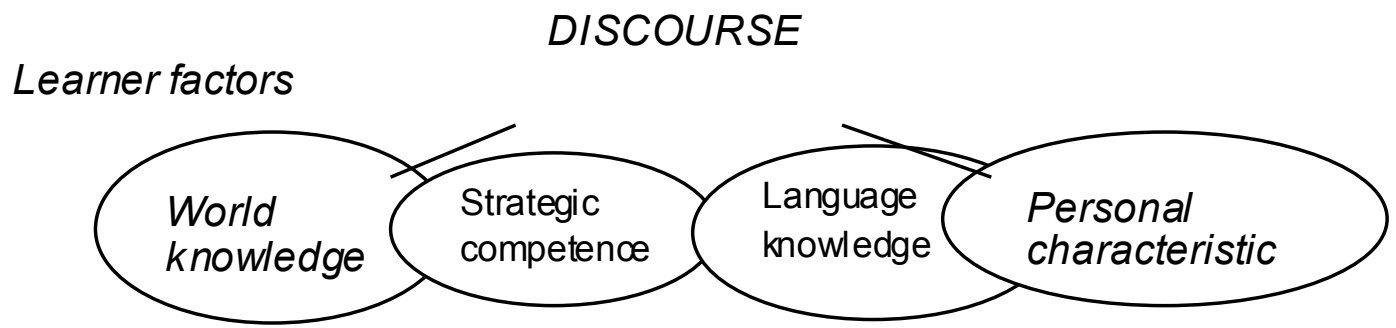

Tasks characteristics

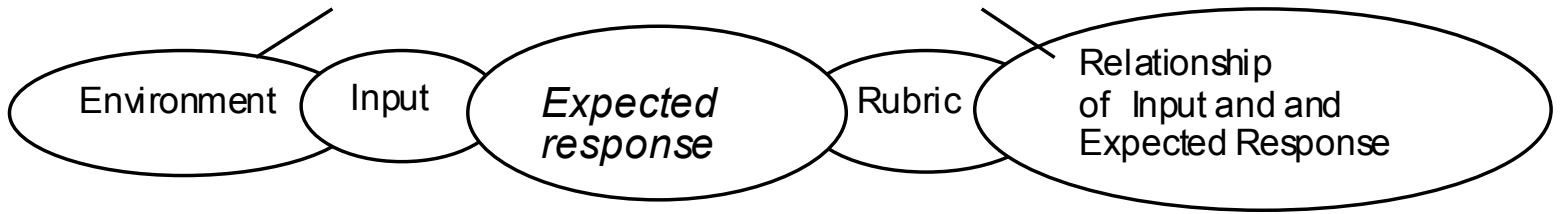

Contextual Factors

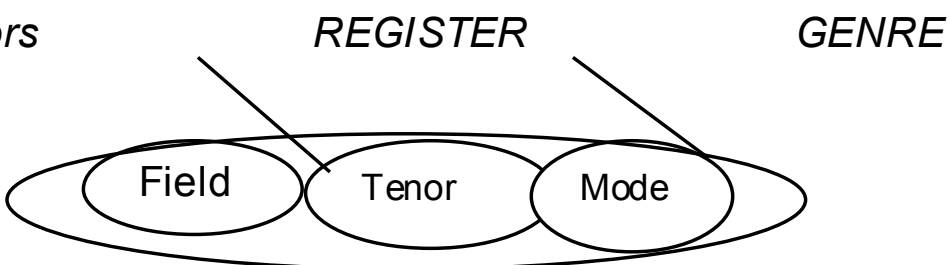

We can start reading the model from the middle (test task characteristics) and going downwards (contextual factors), finish up with the leamer factors in the top part of the diagram. Let us see how it works. Whenever we design a task, be that to be used as a class activity, as an assignment or as a test, we have to take good care of certain characteristics which can facilitate or halt the succesful execution of the task set. If we, as teachers plan any language task bearing those characteristics in mind and making them explicit, we can facilitate the process. If, besides that, we help our students identify what is being demanded from them in each task (rubric and expected response), what type of material they are faced with (input), how quickly they will have to process it and how their responses become input in some kinds of tasks such as conversations, we can greatly contribute to the development of their autonomy. For a complete presentation of these characteristics, see Bachman and Palmer (1996: 48-59).

Besides that, we can help our students discover how a text is affected by the context, how "the text -and therefore the lexical, grammatical and semantic preferences of an author in a text- codes and interprets both the context of the situation (register) and the context of culture (genre)," how "the text is a 
realization ${ }^{2}$ of the different types of context as well as the realization of what is important to the members of a culture in the different situations," as Eggins and Martin (1997:364) pose in van Dijk's book, "Discourse as process and structure." Let us remember how the studies of context have evolved.

In 1985, Halliday proposed a model of context that fitted his model of language organization which was composed of three metafunctions: ideational, interpers onal and textual. Here we include the correspondence between the two models.

\begin{tabular}{|c|c|}
\hline $\begin{array}{l}\text { Metafunction } \\
\text { (Language Organization) }\end{array}$ & $\begin{array}{l}\text { Register } \\
\text { ( Context Organization) }\end{array}$ \\
\hline $\begin{array}{l}\text { Interpersonal meaning } \\
\text { (resources to build up interaction) }\end{array}$ & (structure of roles) \\
\hline $\begin{array}{l}\text { Ideational meaning } \\
\text { (res ources to build up content) }\end{array}$ & (social action) \\
\hline $\begin{array}{l}\text { Textual meaning } \\
\text { (resources to organize texts) }\end{array}$ & $\begin{array}{l}\text { Mode } \\
\qquad \text { (symbolic organization) }\end{array}$ \\
\hline
\end{tabular}

\section{Chart 1. Functional organization of language in relation to the categories used to analyze context in Eggins and Martin (1997:347)}

Register, (last part of the diagram), is detemined by the field, the tenor and the mode. The field specifies the location(s), topic(s), and action(s) present in a particular language context and can range from daily-life/common-sense contexts to more technical/specialized ones. The tenor makes reference to the role of participants (social critics, educators, politicians, etc.), their relationships in terms of power, frequency of contact and degree of affective commitment among them ${ }^{3}$, and their objectives. The mode refers to the symbolic organization of the text, which is chosen depending on the channel used, oral or written and on the speaker or writer's intention, and which is determined by more or less use of nominalizations, personal references, action verbs or complex noun phrases which, in turn, will establish greater or shorter distance between author and reader or listener.

Later on, in 1992 J.R.Martin and his colleages complemented the model with another layer of context called "genre" which is above the layer of register. Their

\footnotetext{
2 According to Eggins and Martin, realization is understood as the relationship established between the language metafunctions and the variables of context (fi eld, mode and tenor). Seen from the perspective of context it refers to the way different kinds of fields, modes, and tenors determine the interpersonal, ideational, and textual meanings; seen from the language perspective, it refers to the way how different choices in the metafunctions produce different types of variables of context.

${ }^{3}$ As it was suggested by Poynton in 1985, according to Eggins and Martin (1997). 
work focused on "making explicit which combinations of field, tenor, and mode are possible in a culture and how they are projected as social processes." Discourse genres have been defined as "relatively stable" kinds of interactive acts of communication which are classified based on their social purposes. Genres can be both literary and everyday life ones.

Once learners understand the contextual factors, they use their strategic competence to act upon their world and language knowledge to understand and produce discourse ( top part of the diagram). It is important to keep in mind that students' pers onal characteris tics underlie and therefore influence the other leamer factors.

Goal 2. To foster the achievement of the second goal, we can use Rebecca Oxford's taxonomy of learning strategies (1990) and Bachman's concept of strategic competence which help us reflect upon the mental processes brought about when faced with a language task.

In our model, we think learners will learn better if they talk about and set their own language learning goals because this allows them to make choices and encourages a sense of personal responsibility (Williams and Burden, 1997:206). Choosing strategies, establishing plans, and monitoring them will help them be more self-dependent, more self-confident and more open to challenges. Continuous self-assessement will make them more aware of their difficulties as well as their improvements. All of these factors contribute to build up leamer autonomy.

\section{Cooperative Assessment}

The preparation for and execution of peer-assessment (steps 6 and 7), on the other hand, foster the interaction among students, which is an integral part of the language leaming process and which, according to Vigostsky, is the secret of effective learning. As Williams and Burden point out, these interactions can develop a sense of belonging; they can encourage cooperative work and personal control. However, as it will be explained later, this process also promotes autonomy since students are free to choose different activities to assess their partners.

\section{Formal Assessment}

As classes and strategy training went on, we tried to design test tasks in which characteristics such as clarity, appropriacy, reliability, authenticity and fairness were built in, process called formal assessment in the model. This activity has been successfully carried out thanks to intense team work and lots of humbleness and empathy among teachers-researchers. The three components of the discourse domain, that is, the field, tenor, and mode were also taken into account when planning every test task and clearly stated when designing them.Once students were faced with a task, we suppose, they were able to activate their strategic 
competence in order to understand what they were asked to do, set goals to be able to cope with the task, monitor and self-evaluate their performance as they were carrying out the task, and, finally, make the necessary adjustments to their final product.

\section{Model of autonomous learning and cooperative assessment, Vera et al. $^{4}$}

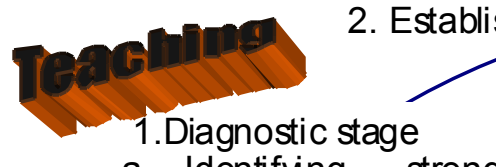

a. Identifying strengths and weaknesess

b. Identifying specific problems

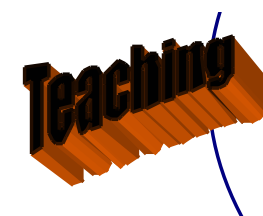

8. Handling of results and feedback

\section{Autonomous Learning}

\section{s}

3Choosing strategies and establishing
4. Monitoring plans and strategies

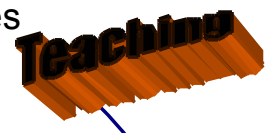

5 - Self-assessment of:

- Production

- Abilities

- Plans and strateaies

6. Knowledge of test design, administration and grading.

7. Peer- assessment, feedback and self-

Taken as a basis for the cooperative and autonomous view of our model, the language learner model designed by Naiman, Frolich, Todes $\infty$ and Stern, presented below, gave us, initially, a general view of the psychological and sociological aspects that affect learning and made us think about the necessity of paying more attention to factors we had set as ide in our class room management.

The model shows a range of potential factors that influence the success on language learning. The first three factors of the figure, teaching, the learner, and the context- each composed of other specific elements that have to be determined

4 The co-researches were: Luz Dary Arias, Zulma Buitrago, Luis Fernando Gómez, Miryam Marin de Otálora, Cecilia de Roa, and Clara I. Quiroga. 
such as quality of instruction, kind of resources, leamer characteristics, social and cultural milieu, etc.- affect learning.

Learning, as seen by Naiman et. al., is constituted by the unconscious processes the student follows to develop competence in the target language and the kind of strategies he uses consciously to be more successful. The unconcious processes such as generalization, simplification and transfer can help or hinder language learning. Generalization refers to the application of morphological, syntatic and phonological rules to similar contexts whether it is correct or not. Simplification takes place when the learner chooses to use the less complex rules or the vocabulary he or she is more familiar with. Tranfer occurs when the leamer uses the rules of his $L 1$ to explain linguistic phenomena of the $L 2$. The conscious processes, which imply some degree of leamer control, include strategies that greatly contribute to fostering language leaming.

Nevertheless, the leamer strategy taxonomy Rod Ellis did in 1985 shows that generalization, transfer and simplification can also be considered learning strategies. We agree with him because it is difficult to determine which of those processes are conscious and which one are unconscious and because, in the end, all of them are tactics leamers use.

In turn, the whole leaming process influences the leaming proficiency and the qualitative aspects of perfom ance such as errors and affective reactions towards learning itself, the people involved in it and the L2 and its culture.

Keeping this model in mind, in regards to the learner, we focused our attention on attitudes, some traits of personality, and learning styles because those aspects can be influenced a bit more than the others. 
THE GOOD LANGUAGE-LEARNER MODEL Naiman, Frolich, Todesco, Stern (1978) en Skehan (1984:4)
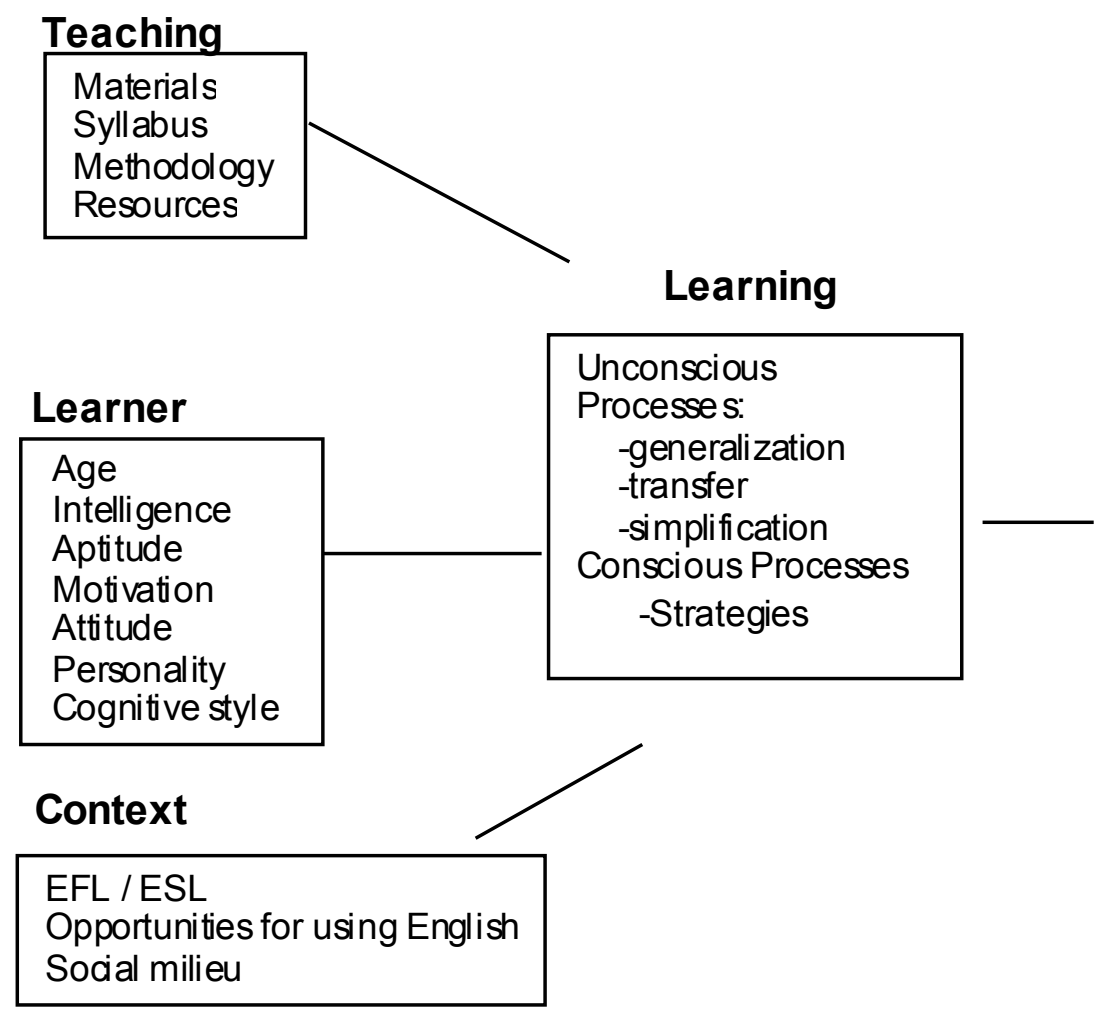

Outcomes

Competence

- $\quad$ Listening

- Speaking

- Reading

- Writing

Errors

Interlanguages

Affective

Reactions

Later on, we analyzed two interactionalist models: Bachman \& Palmer's (op.cit.) and Chapelle's models. In order to have a wider perspective of the factors intervening in language use and testing, we integrated such models and Naiman's into the adapted version we analyzed at the beginning. What was considered as learner factors in Naiman's model has become the personal characteristics component in Chapelle's, but she has considered other three components -world/ topical knowledge, language knowledge, and strategic competence- that she took from Bachman's model.

$1^{\text {st }}$ step: Getting to know the learners

Taking a humanistic approach which "emphasizes the importance of the inner world of the learner and place the individual's thoughts, feelings and emotions at the forefront of all human development" (Williams y Burden, 1997:30), we looked for questionnaires which could help us get a better view of both our students' feelings and cognitive preferences. 
Through questionnaires, we started by determining the students' learning styles, their brain dominance, and their attitudes towards the evaluation process. Regarding the leaming

styles, we found that $56 \%$ of the 200 students included in the study ${ }^{5}$ were visual, followed by a $12 \%$ of auditory style,only $5.7 \%$ of tactile style. We also found the percentage of students with combinations of styles was low: $5.2 \%$ audio-visual, $3.6 \%$ visual-tactile and only $1 \%$ with the three styles.

Graph 1.

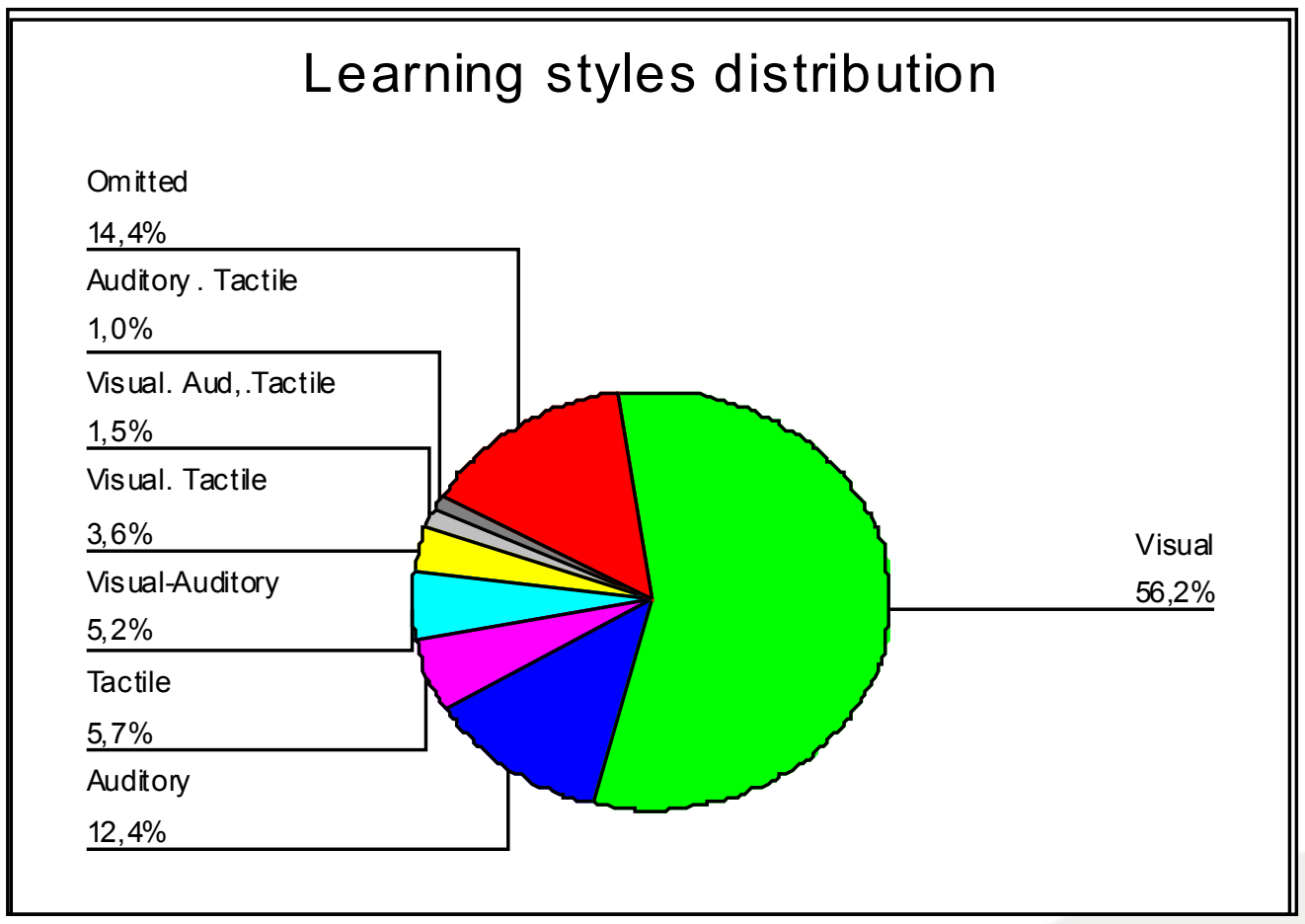

The fact of being aware of the different learning styles has affected not only our teaching methodology, since now we try to cater for all the needs students have in this area but also the students' study habits. Now learners are more aware of the way they learn better and of other ways of learning they can use to complement their styles; that definitely contributes to develop their autonomy.

In the same fashion, we tried to find out which brain hemisphere is used more predominantly by our students. We found that the biggest percentages are concentrated in the slight left dominance area, $35,6 \%$ and in the slight right dominance area, $25.8 \%$. This results differed greatly from the strong left

\footnotetext{
${ }^{5}$ The population of this study was students of language programs, (English); the sample was constituted by 9 groups: 3 groups of Basic I, 3 groups of Basic II, 3 groups of Intermediate I, each level with 2 experimental groups and 1 control group.
} 
dominance people nomally expect to find in language students, since the verbal processes are said to be controlled by the left hemisphere.

One interesting finding was that these students with slight right or left dominance were the ones who obtained the best results in the formal evaluations. We think the advantage they seem to have is that they can easily use processes governed by the hemis phere which is

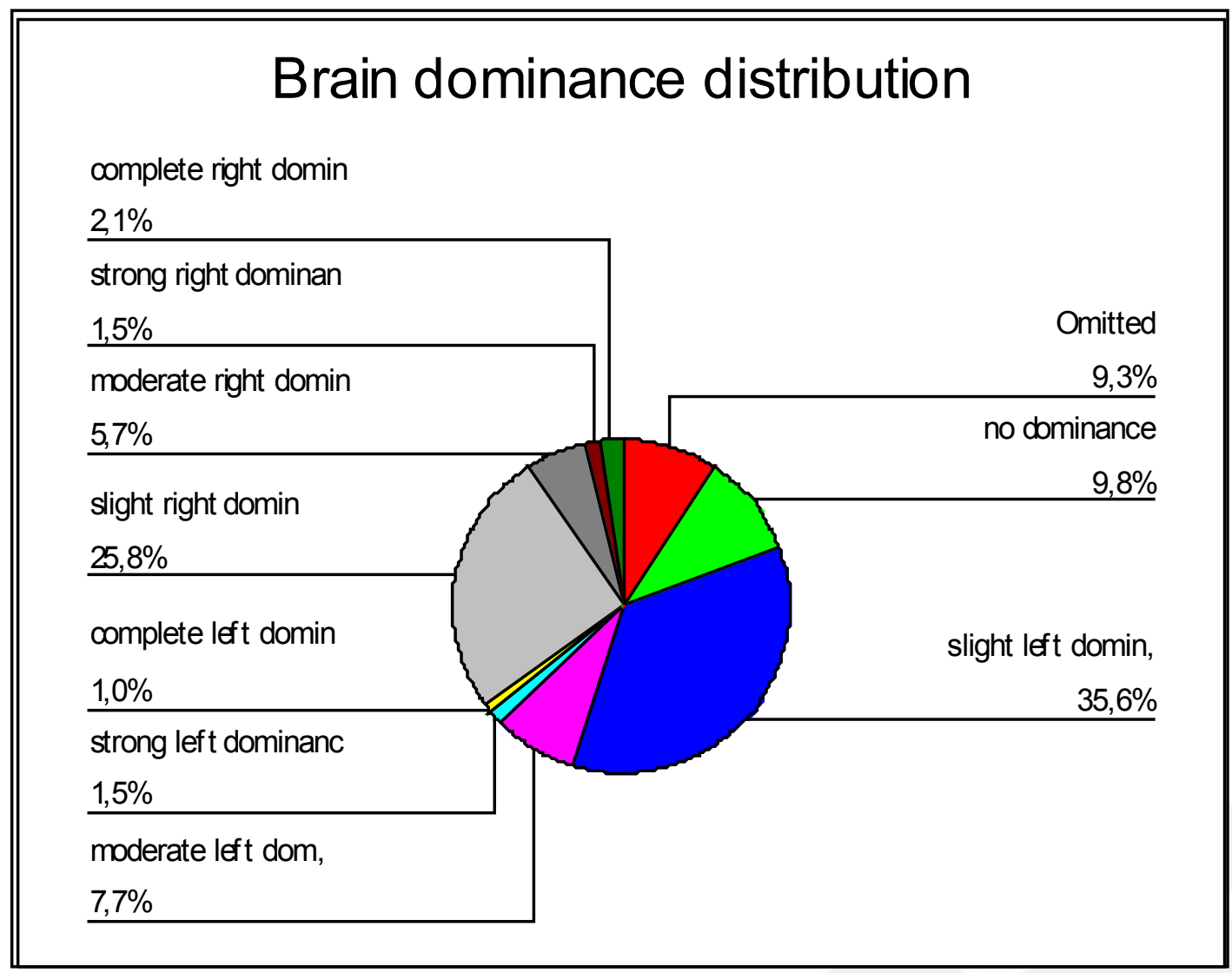

not dominant in them. Now that we know that we are trying to include in our class room activities that promote the use of both hemispheres.

We also tried to find out more about their background knowledge acquired in other institutions, whether they were repeating the semester or not, and if they had an internal locus of control, that is, if they usually assumed their failures as their own responsibility. Regarding this last factor, we found that only a little percentage of students $(5 \%)$ show an internal locus of control; most students showed a mixed locus, that is, for some situations they show an external locus and for others they show an internal one. The only significant correlation we found related to locus of 
control was with repetition; a correlation ${ }^{6}$ of 0.18 in a sample of 111 students (significance at 0,058 ).We could also notice that only one of the 3 control groups contained students who had studied at other institutions and students who were repeating the semester $(30 \%)$.

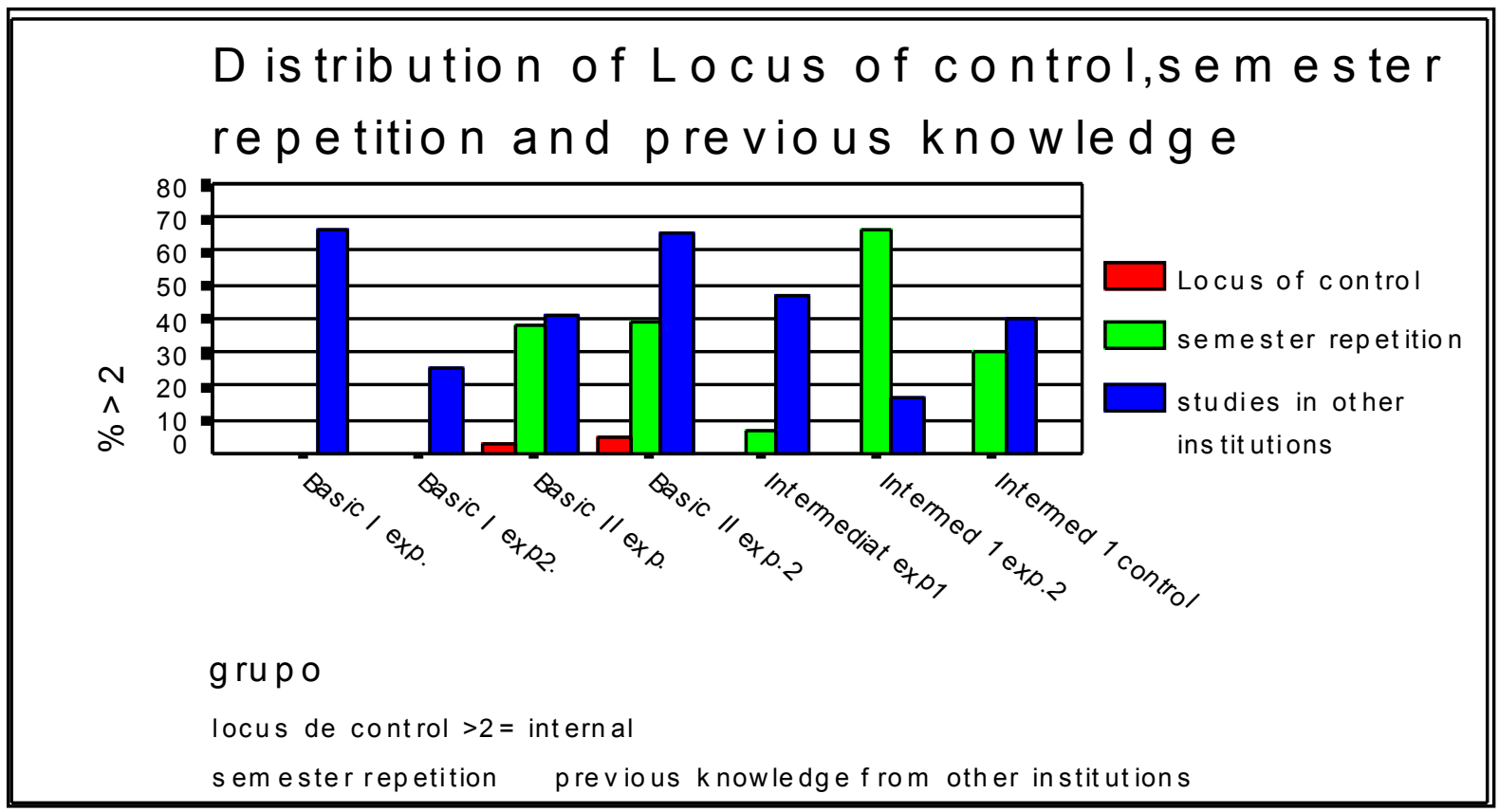

We took these characteristics into account because we thought both could influence the students' language proficiency and their attitudes towards evaluation. The first hypothesis was confimed by the results since they showed that there was correlation of $0,30\left(\mathrm{~N}=191\right.$, Sign. $\left.=0,0^{7}\right)$ between previous knowledge and Partial 2 , and a correlation of $0,20(N=165$, Sign $.=0,009)$ between previous knowledge and the post test; no correlation was found with Partial 1, though. However, no significant correlations were found between semester repetition and the results of the evaluations or with the students' attitudes toward evaluation.

Our null hypothesis in this research project was that the use our our model of evaluation would neither produce significant changes in our students' attitudes toward evaluation and nor would it improve their academic progress in English. This hypothesis can be rejected since, in fact,the use of the model not only produced changes in the unfavorable attitudes of students toward evaluation in the experimental group, as we can see in chart 3 , but also improved the academic progress of the students in the experimental group, as can be seen in chart 4 below.

\footnotetext{
${ }^{6}$ For ordinal variables the Spearman correlation was used; for nominal variables, the Pearson correlation was used.

${ }^{7} \mathrm{~N}$ represents the number of individuals participating in the study and Sign. stands for level of significance. 

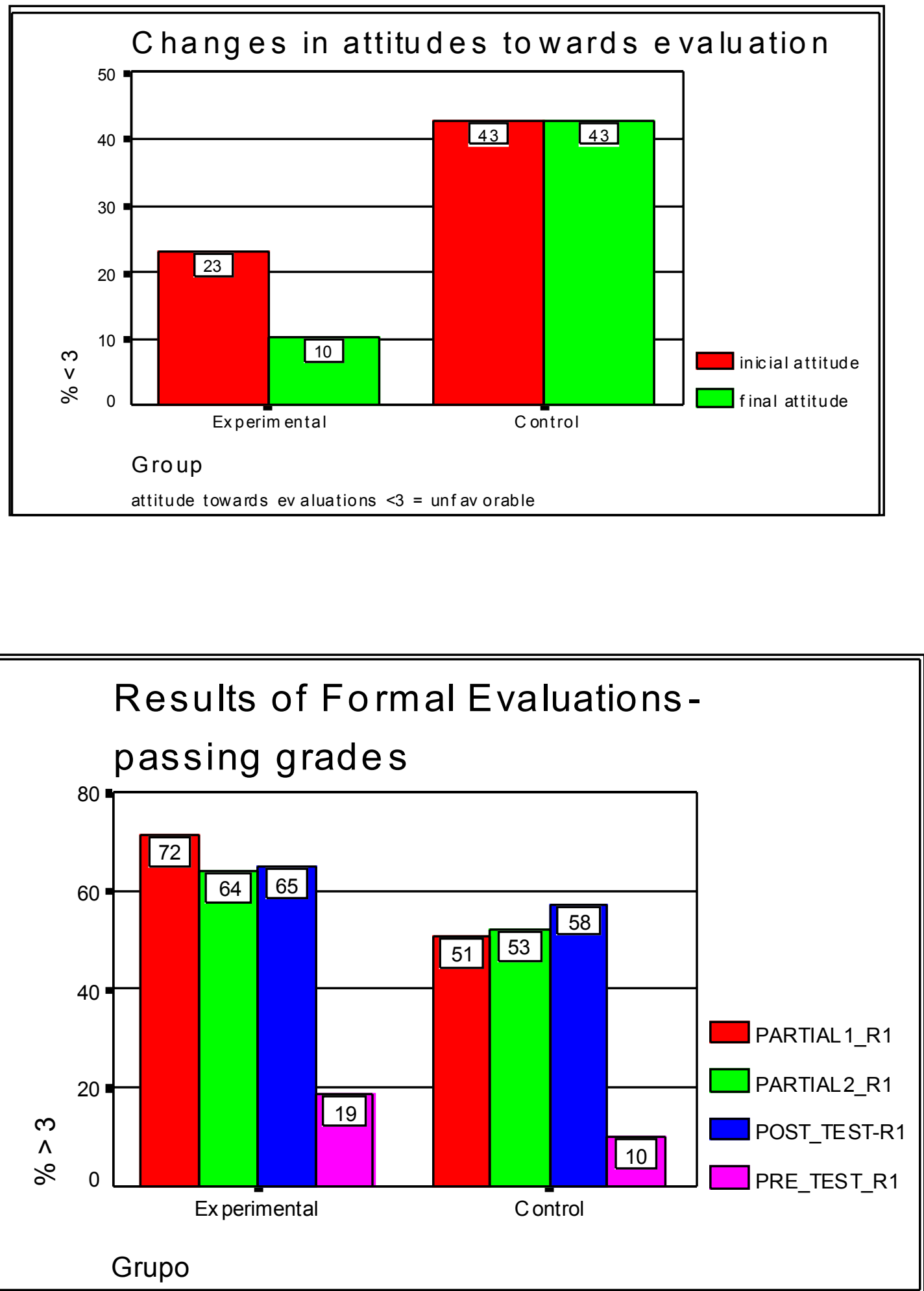


\section{$2^{\text {nd }}$ step: Fostering the development of strategic competence}

Besides getting to know our students, we have tried to get them accustomed to using not only the three components of strategic competence proposed by Bachman -goal setting, planning and evaluating- but also other learning strategies. Consequently, we have worked on making them aware of the importance of using cognitive, social, affective, compensation and metacognitive strategies such as setting goals and planning before starting a task and monitoring and selfassessing their language comprehension and production as they carry out the task.

\section{Learning strategies}

One of the key factors to encouraging students' autonomy, is the concept of Learning Strategies which can be defined as steps used by learners to foster their own learning. They help them work on their own with the help of the teacher who becomes a facilitator of the process. These strategies help us be aware of what we go through when leaming the language and when using it. In addition, they are valuable tools for both teachers and students to maximize and facilitate the language leaming process.

Several researchers, such as O'Malley and Chamot, Anderson, Tarone, R. Oxford, have studied leaming strategies and have presented diverse classifications. However, for our purposes, we have based our experience on Rebecca Oxford's classification, of course, making some changes.

We chose Oxford' classification because it is more comprehensive, detailed and practical. She dassifies strategies into two types: Direct and Indirect ones. According to her point of view Direct Strategies are steps that involve the target language and require mental processing of the language. Indirect Strategies support and adm inister language learning, without involving the target language.

Direct strategies include Memory strategies, which help "store and retrieve new information;" Cognitive strategies, which help the leamer "understand and produce new language by using many different means;" and Compensation strategies, which help learners communicate a message using different ways, even when they have a gap in knowledge.

Indirect strategies include Metacognitive strategies, which allow learners to control their leaming; Affective strategies, which help students enhance learning by regulating "their emotions, motivations and attitudes;" and Social strategies, which help communication by_negotiating information with other speakers.

Nevertheless, we do not consider Memory strategies and Cognitive strategies should be taken separately, since both types involve mental processing. Thus, Memory strategies imply storage and retrieval of new information which can then be used in manipulating and transforming the language by using cognitive 
strategies. They are not mutually exclusive but rather they complement and empower each other. Also, we believe that using linguistic and other clues are not exclusively related to Compensation strategies but also to Cognitive ones in that they imply logical analysis and reas oning of the target language.

As Rebecca Oxford points out, leaming strategies are directed toward the big goal of achieving Communicative Competence which is composed of Grammatical Competence, Discourse Competence, Sociolinguistic Competence, and Strategic Competence according to Canale and Swain's point of view. Learning strategies help students engage in meaningful situations where they can interact with their peers or the teacher to get their meaning across. For instance, cognitive strategies, help students improve their Grammatical Competence due to the fact that their use allows students to analyze structures contrastively, reason deductively, and establish relationships between what is already in memory and new information. Compensation, social, and cognitive strategies, help students develop Discourse Competence as they facilitate authentic communication to take place. Social strategies, encourage Sociolinguistic Competence by facilitating interaction with peers, the teacher or native speakers. Finally, Compensation strategies aid Strategic Competenc ${ }^{8}$ by helping students overcome understanding and communication gaps.

\section{Strategy Training}

According to Oxford, the process of Strategy assessment and training involves two stages: identification or diagnosis of strategies used by leamers, and training. The identification or diagnosis stage can be developed through such techniques as interviews, observations, note-taking. Interviews are techniques in which leamers perform a language task and say how they are fulfilling it or, without accomplishing a task, they describe the processes they normally follow to cope with a task just given by the teacher. In observations, the students give the teacher information about activities that are directly observable and that can be registered by taking impressionis tic or structured notes. Note-taking can be achieved by having a group of learners write down their learning difficulties when accomplishing a language task or filling out a grid daily prior to an interview or having them describe the strategies they use.

In addition to using these techniques, we have implemented the SILL (Strategy Inventory for Language Learning) that was designed by Rebecca Oxford in order to help students analyze and be aware of many different learning strategies they can use to enhance their leaming. By completing this inventory, we have helped our students think consciously of learning strategies for the first time and discover to what extent they have used them or not in their learning process up to that moment.

\footnotetext{
${ }^{8}$ It is important to mention that we differ from Oxford's point of view in that we consider strategic competence in a broader sense, since we believe all the strategies mentioned influence its development. 
After this diagnostic stage, by means of which the teacher knows how the students are learning, comes the training process. Based on the results obtained on the SILL, teachers guide and provide students with tasks where they can then use a wider variety of strategies which range from the planning stage to the selfevaluation stage where sudents have the chanœe to check whether their application of different strategies was effective or not. Thus,

we, as teachers, have performed different tasks and taken notes on the strategies we used to develop the tasks, and then we have asked students to do the same tasks in order to have them self-evaluate on which strategies they used from the options offered by the teacher, and how effective these were in accomplishing the given task(s).

Other strategy training techniques are the use of diaries, in which leamers register their feelings, achievements, and problems in leaming; and self-report surveys used to gather written information about language leaming strategy use.

Our experience with learning strategies has been enriching due to the fact that they have contributed to both teachers and students to have a better and more conscious understanding of the variety of tools one can use when learning a language. In addition, they have constituted an important factor in our search to foster autonomy in the learning process of our future language teachers.

\section{Self-assessment}

The self-assessment process is considered as one of the metacognitive strategies by both R. Oxford and M. O' Malley \& A. Chamot in the classification they made; however, they do not include peer-assessment as such in their lists. We do include it as a very important process due to the pedagogical emphasis of our language programs.

The self assessment process was carried out after each formal test before students received the result. Each student was given a format with the list of aims for the term, in which he had to mark if he considered he had or hadn't reached them. After receiving the results of the formal test, they had to confront them with the self assessment format and explain any differenœes between what he believed he knew and what he had shown he knew in the test.

It was also carried out through the compositions students had to turn in. They handed in a draft which the teacher checked to tell them what kind of mistake they had made and, afterwards, the students had to correct it using a correction key for compositions they had been given at the beginning of the semester. The teacher, then, graded the writings comparing the draft with the final version of the paper. The students kept a record of their most frequent mistakes in order to see their progress. 
This self assessment process helped the students get more responsibility and autonomy and promoted the use of learning strategies which help the leamer improve SLA.

\section{Peer-assessment}

They have also been engaged in formal peer-assessment activities twice during the semester with the guidance of their teachers. This process has been carried out as preparation for two of the three formal evaluations students nomally take along the semester. Students have found this activity enriching not only because they have the possibility to experience a teacher's duties in relationship to evaluation but also because they are trained in the basic principles of test design, administration and grading. For the purpose of peer-assessment, the students write a draft of the test to be checked by the teacher, then they revise it to write the final version. Afterwards, they administer and grade the tests in order to give their partners feedback on their perfomance. This peer evaluation process has some other positive outcomes:

1. Students acquire experience as language teachers.

2. They get conscious of the difficulties teachers face when dealing with testing.

3. They become aware of the whole cycle of evaluation in the class room.

4. It is useful as an informal self-assessment process for the students who participate in the activity because it helps them identify their strengths and weaknesses, not only as preparation for the formal evaluation but also for all their learning process.

5. It enhances students' autonomy and critical attitude.

\section{Conclusions}

We can state that the model of autonomous learning and cooperative evaluation which embarks the four processes just mentioned, has helped students improve their language command and become more autonomous and cooperative since they are now more aware of the way they learn and conscious of the several traits that influence their learning process. Furthermore, they have been considered active participants of the whole evaluation cycle, and, in that way, they have experienced the role of language teachers, which, in turn, has helped them change positively their attitudes towards the teacher and the evaluation process, and become more organized. 
From this experience we can draw the following conclusions:

Learning Styles

$\checkmark$ Students who know their learning styles can realise which activities they can benefit more from

$\checkmark$ Teachers who know their students learning styles can change the way they organize and execute classroom activities so as to cater for all their students' needs in terms of learning preferences.

Learning Strategies

$\checkmark$ Teachers who become aware of and use a great deal of leaming strategies can guide their students in a better way through their learning process, since they can foresee the difficulties students are going to encounter and help them be prepared to overcome them.

Factors affecting discourse

$\checkmark$ Teachers who understand the contextual factors that influence a text can teach their students to identify those factors in order for them to understand, produce, monitor and assess discourse.

Self-assessment

$\checkmark$ Students who undergo self-assessment processes become more aware of the weakness and are able to judge their achievements more honestly.

Peer-ass essment

$\checkmark$ Students who experience the processes of test design, administration and grading are more likely to understand the teacher's role regarding evaluation and be better prepared to perform as future teachers in being more fair when assessing their students.

$\checkmark$ Students who take part in the peer-assessment processes learn to be more critical but, at the same time, more tolerant in their daily interaction.

$\checkmark$ Students who receive feedback on how they did in formal evaluations are empowered to identify their strengths ans weakenesses and start a new process involving the different stages of our model of autonomous leaming and cooperative assessment. 


\section{BIBLIOGRAPHY}

BACHMAN, L. y PALMER, A. (1996) Language Practice Testing. Oxford: Oxford University Press.

CHAPELLE, C. (1998) Construct Definition and Validity Inquiry in SLA. En: BACHMAN

L. y COHEN, A. Interfaces between Second Language Acquisition and Language Testing Research. Camb ridge: Applied Linguistics. Cambridge.

EGGINS, S. and MARTIN J.R. (1997) Géneros y registros del discurso. En: DIJK VAN, T. El discurso como estructura y proceso. Barcelona: Gedisa.

HOLEC, H. (1979)Autonomy and Foreign Language Learning. Oxford: Pergamon Press.

O'MALLEY, M. and CHAMOT, A. (1990) Learning Strategies in Second Language Acquisition. Cambridge: Cambridge Applied Linguistics.

OXFORD, R. (1990) Language Learning Strategies. Boston: Heinle \& Heinle publishers.

WILLIAMS, M. and BURDEN, R. (1997) Psychology for Language Teachers: a Social Constructivist Approach. Cambridge: Cambridge University Press. 